\title{
Kinetic Model of Wastewater Treatment in Horizontal Flow Flotation Tank
}

\author{
Ekaterina Sergeevna Antonova', Dmitry Vasil'evich Sazonov ${ }^{1 *}$ \\ 1 Ecology and industrial safety department, Bauman Moscow State Technical University (BMSTU), build. 1, 5, \\ 2-nd Baumanskaya St., 105005, Moscow, Russian Federation \\ * Corresponding author's e-mail: sazonov-d@bmstu.ru
}

\begin{abstract}
The flotation wastewater treatment was considered in the paper. The main stages and parameters of flotation process were pointed out. The multistage flotation model considering all main stages of flotation process is presented. However, its main disadvantage is that for the definition of constant characterizing the bubble-particle aggregate formation, the constant value of superficial gas velocity was used, which is incorrect for horizontal flow flotation tank. The modified multistage flotation model with superficial gas velocity as the function of time was proposed. The experiments were carried out on a laboratory setup with a pneumohydraulic system of aeration in order to verify the proposed model. The comparison of experimental and theoretical results proved the importance of superficial gas velocity change consideration.
\end{abstract}

Keywords: flotation; mathematical model; wastewater treatment; horizontal flotation tank

\section{INTRODUCTION}

Flotation is commonly used in wastewater treatment technologies. During the flotation, the wastewater is aerated with air bubbles, while the particles of contamination form bubble-particle aggregates and rise into the froth layer [Prakash et al., 2018; Saththasivam et al., 2016]. The flotation process is quite complicated and depends on many factors. The main parameters that influence the flotation efficiency are the parameters of aeration system and contamination, such as size of bubbles, superficial gas velocity, hydrophobicity of contamination, size of particles, density, rising velocity of bubble-particle aggregate [Kouachi et al., 2010; Kracht et al., 2005; Shahbazi et al., 2013]. Mathematical modelling of this process plays an important role in the development of flotation tanks. It enables to predict the time and efficiency of the process as well as define the main constructional parameters of flotation tank [Guerrero-Pérez and Barraza-Burgos, 2017]. There are different mathematical models of flotation, for example, first-order flotation model, flotation models with higher orders, adsorption models [Brożek and A. Młynarczykowska, 2007; Polat and Chander, 2000; Yianatos, 2007]. However, the most existing models do not consider all peculiarities of flotation. It is a complicated, multistage process. As there are different opinions on the flotation mechanism, the main stages are in general the following: collision of particle and bubble, bubble-particle aggregate formation, rise of bubble-particle aggregate, froth layer formation [Bu et al., 2017; Cheng et al., 2017; Edzwald, 2010]. Moreover, some particles of contamination with the density, lesser than the density of water, can rise, increasing treatment efficiency. However, there are some negative processes such as bubbleparticle detachment, separation of bubble-particle aggregate from froth layer and sedimentation of particles from the froth layer [Cheng et al., 2017; Gurung et al, 2016; Ksenofontov, 2010].

The mathematical model that considers the main stages of the flotation process is presented in Figure 1, where $A$ - initial state of particles; $B$ - contamination in the state of bubble-particle aggregate; $C$ - state of contamination in the froth 
layer; $k_{i}, \mathrm{~s}^{-1}-$ constants of transition between stages [Ksenofontov, 2010].

The process is described by the system of differential equations (1) with initial conditions (2):

$$
\left\{\begin{array}{c}
\frac{d C_{A}}{d t}=-\left(k_{1}+k_{6}\right) C_{A}+k_{2} C_{B}+k_{5} C_{C} \\
\frac{d C_{B}}{d t}=k_{1} C_{A}-\left(k_{2}+k_{3}\right) C_{B}+k_{4} C_{C} \\
\frac{d C_{C}}{d t}=k_{6} C_{A}+k_{3} C_{B}-\left(k_{4}+k_{5}\right) C_{C} \\
C_{A}(0)=C_{A 0} ; C_{B}(0)=C_{C}(0)=0
\end{array}\right.
$$

where $C_{A}, C_{B}, C_{C}$ - concentrations of the particles in the states $A, B$ and $C$.

Constant $k_{1}$ characterizes the bubble-particle aggregate formation probability. It can be calculated with Eq. (3):

$$
k_{1}=\frac{1.5 q E}{k_{0} D}
$$

where $q$-superficial gas velocity, $\mathrm{m}^{3} /\left(\mathrm{m}^{2} \cdot \mathrm{s}\right)$,

$E$ - efficiency of bubble-particle aggregate formation (dimensionless);

$D$ - average diameter of the bubbles, $\mathrm{m}$;

$k_{0}$ - polydispersity factor (dimensionless).

In this formula superficial gas velocity is constant and can be defined by Eq. (4):

$$
q=\frac{Q_{a i r}}{S}
$$

where $Q_{\text {air }}-$ air flow rate, $\mathrm{m}^{3} / \mathrm{s}$,

$S$ - cross-sectional area of flotation tank, $\mathrm{m}^{2}$ [Eskin, 2017; Vazirizadeh, 2015].
The rise of the bubble-particle aggregate is characterized by constant $k_{3}$ :

$$
k_{3}=\frac{v_{a g}}{h}
$$

where $v_{a g}$-rising velocity of bubble-particle aggregate, $\mathrm{m} / \mathrm{s}$;

$h$ - height of water layer in flotation tank, $\mathrm{m}$.

Other constants characterize reversible processes $\left(k_{2}, k_{4}, k_{5}\right)$ and the process in which particles rise themselves $\left(k_{6}\right)$ can be defined experimentally or according to [Ksenofontov, 2010].

\section{Modified model}

However, the superficial gas velocity can change in real horizontal flow flotation tanks. Such flotation tank with bubble supply in the beginning of the apparatus was considered in this work. In this case, there are three zones in the flotation chamber (Figure 2): I - zone of intensive aeration; II - intermediate zone; III - zone of low aeration.

The first zone is the zone with turbulent flow where aeration and bubble-particle aggregate formation occur. The superficial gas velocity in this zone is high and constant. The flow in second zone is less turbulent, so the bubble-particle aggregate and free bubbles rise and the superficial gas velocity becomes lower. The bubble-particle aggregate formation process continues, but not so effective. In the last zone, free bubbles are almost absent, and the least bubble-particle aggregates rise. As free bubbles rise during the whole process, it is incorrect to consider that the superficial gas velocity is constant and use the average value. At the beginning of the flotation process,

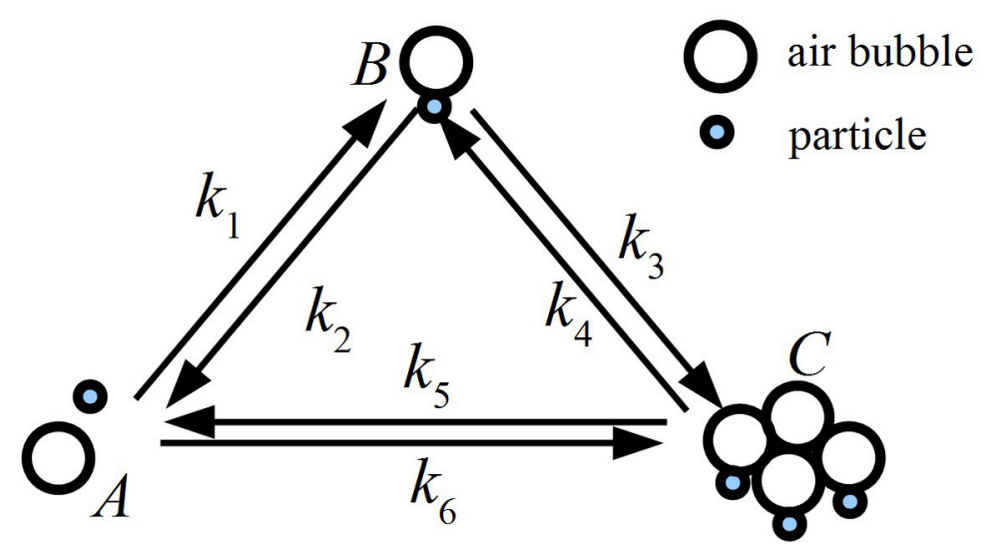

Figure 1. Scheme of flotation process 


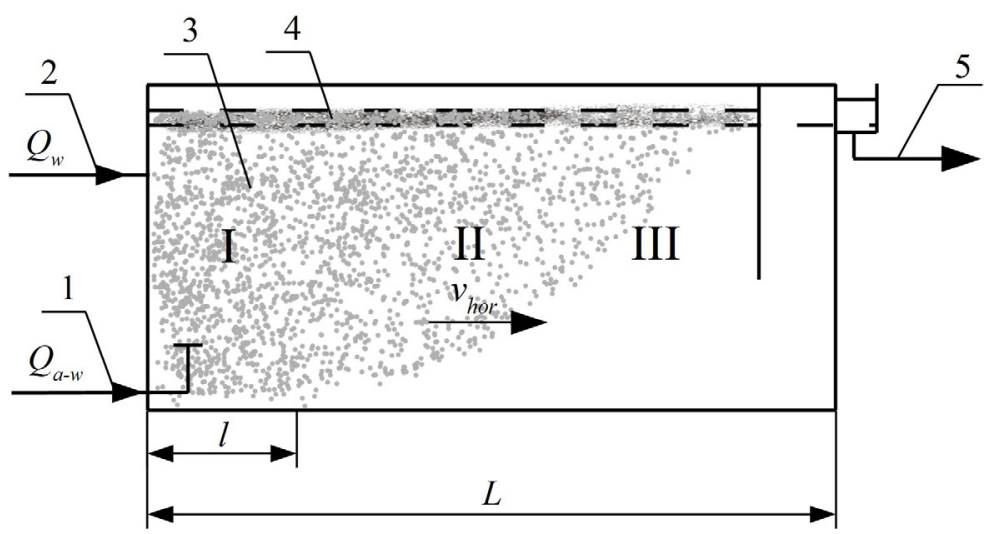

Figure 2. Horizontal flotation tank:

1 - air-water mixture inlet; 2 - wastewater inlet; 3 - air bubbles; 4 - froth layer; 5 - treated water outlet

the superficial gas velocity is much larger than the average value. As bubble-particle aggregate formation process occurs mostly in first 5-7 minutes [Haarhoff and Edzwald, 2004], the use of its average value in mathematical simulation of the process can lead to incorrect results and demand surplus air flow rate, which increases operational costs. Moreover, the main purpose of modelling is to predict more exact time of flotation in order to calculate the geometrical parameters (length, width and height) of flotation tank, and as the value of cross-sectional area is unknown, it can be only taken approximately.

Thus, the flotation model was modified according to these circumstances.

The following parameters were used:

$Q_{\text {air }} \mathrm{m}^{3} / \mathrm{s}$ - air flow rate;

$Q_{w}, \mathrm{~m}^{3} / \mathrm{s}$ - treated water flow rate;

$Q_{a-w}, \mathrm{~m}^{3} / \mathrm{s}$ - air-water mixture flow rate;

$Q_{\Sigma}=Q_{w}+Q_{a-w}-$ total water flow rate;

$k_{a-w}=\frac{Q_{a-w}}{Q_{w}}-$ ratio of air-water mixture and treated water flow rates;

$$
k_{\text {air }}=\frac{Q_{\text {air }}}{Q_{a-w}}-\text { ratio of air and air-water mix- }
$$

ture flow rates;

$$
\varphi=\frac{Q_{a i r}}{Q_{\Sigma}}=\frac{k_{a-w} \cdot k_{a i r}}{1+k_{a-w}}-\text { coefficient of air- }
$$

water ratio.

The following was taken into consideration: firstly, superficial flow rate is constant across the width of flotation tank. Secondly, the rise of bubbles is analogous to the rise of bubble-particle aggregate, so the constant that characterizes the rise of bubbles is:

$$
k_{q}=\frac{v_{b}}{h}
$$

where $V_{b}$-rising velocity of bubbles, $\mathrm{m} / \mathrm{s}$.

Then the function that describes the change of superficial air flow rate is following:

$$
q(t)=q_{0} \exp \left(-k_{q} t\right)
$$

where $q_{0}$ - initial superficial air flow rate.

If the length of the first zone with constant initial superficial air flow rate $q_{0}$ is $l$, the average superficial air flow rate is defined as:

$$
\begin{aligned}
& q_{a v}=\frac{Q_{a i r}}{B L}=\frac{1}{L} \int_{0}^{L} q(x) d x=\frac{1}{L}\left(\int_{0}^{l} q_{0} d x+\int_{l}^{L} q_{0}\left(-k_{q} \frac{x}{v_{h o r}}\right) d x\right)= \\
& =q_{0} \frac{1}{L}\left(l+\left.\left(-\frac{v_{\text {hor }}}{k_{q}}\right) \exp \left(-k_{q} \frac{x}{v_{h o r}}\right)\right|_{l} ^{L}\right)= \\
& =q_{0} \frac{1}{L}\left(l-\frac{v_{\text {hor }}}{k_{q}}\left(\exp \left(-k_{q} \frac{L}{v_{\text {hor }}}\right)-\exp \left(-k_{q} \frac{l}{v_{\text {hor }}}\right)\right),\right.
\end{aligned}
$$

where: $v_{h o r}$ - the velocity of horizontal flow, $x-$ coordinate of distance which varies from 0 (the beginning of flotation tank) to $L$ (the length of flotation tank). In case of $L \geq 3 l q_{0}$ can be defined as:

$$
q_{0}=\frac{Q_{a i r}}{B}\left(l+\frac{v_{h o r}}{k_{q}} \exp \left(-k_{q} \frac{l}{v_{h o r}}\right)\right)^{-1}
$$

Considering that $\frac{l}{v_{h o r}}=t_{1}$ - time of the process in the first zone with constant aeration, where 
the bubble-particle aggregates are mostly formed, the equation for $q_{0}$ is following:

$$
\begin{gathered}
q_{0}=\frac{Q_{\text {air }}}{B v_{h o r}}\left(t_{1}+\frac{1}{k_{q}} \exp \left(-k_{q} t_{1}\right)\right)^{-1}= \\
=\varphi \frac{H \cdot k_{q}}{k_{q} \cdot t_{1}+\exp \left(-k_{q} \cdot t_{1}\right)} .
\end{gathered}
$$

Therefore, the process for the first zone is described by the system Eq. (1) with initial conditions Eq. (2) with $k_{1}=K$ :

$$
K=\frac{1.5 E}{k_{0} D} q_{0}
$$

The process in the second and third zones is described by the Eq. (1) with $k_{1}=k_{1}(t)$ :

$$
\begin{gathered}
k_{1}=k_{1}(t)=\frac{1.5 q(t)}{k_{0} D}=\frac{1.5 E}{k_{0} D} q_{0} \exp \left(-k_{q} t\right)= \\
=K \exp \left(-k_{q} t\right)
\end{gathered}
$$

The initial conditions are:

$$
C_{A}(0)=C_{A}\left(t_{1}\right) ; C_{B}(0)=C_{B}\left(t_{1}\right) ; C_{C}(0)=C_{C}\left(t_{1}\right)
$$

In order to compare the existing and modified models, the system of differential equations Eq. (1) was solved for the following parameters: $k_{a-w}=0.25, k_{a i r}=0.04, t_{1}=300 \mathrm{~s}, v_{b}=3 \mathrm{~mm} / \mathrm{s}$, $v_{a g}=2.5 \mathrm{~mm} / \mathrm{s}, h=0.9 \mathrm{~m}, D=75 \mu \mathrm{m}, k_{0}=1$. The calculation was made for particles with high flotability $(E=0.05)$ and low flotability $(E=0.025)$. The parameters and constants were obtained using Eq. (3), (5), (6), (8), (10), (11): $q_{a v}=2 \cdot 10^{-6} \mathrm{~m}^{3} /$ $\left(\mathrm{m}^{2} \cdot \mathrm{s}\right), q_{0}=1.75 \cdot 10^{-5} \mathrm{~m}^{3} /\left(\mathrm{m}^{2} \cdot \mathrm{s}\right), k_{q}=3.33 \cdot 10^{-3} \mathrm{~s}^{-1}$, $k_{3}=2.78 \cdot 10^{-3} \mathrm{~s}^{-1} ; k_{1}=4.8 \cdot 10^{-3} \mathrm{~s}^{-1}$ and $K=1.75 \cdot 10^{-2} \mathrm{~s}^{-1}$ (for $E=0.05$ ); $k_{1}=2.4 \cdot 10^{-3} \mathrm{~s}^{-1}$ and $K=8.75 \cdot 10^{-3} \mathrm{~s}^{-1}$ (for $E=0.025$ ). The solution of system of differential equations for model with $q=$ const $=q_{a v}$ and $q=q(t)$ is presented in Figure 3a for the particles with high flotability and Figure $3 b$ for the particles with low flotability.

a)

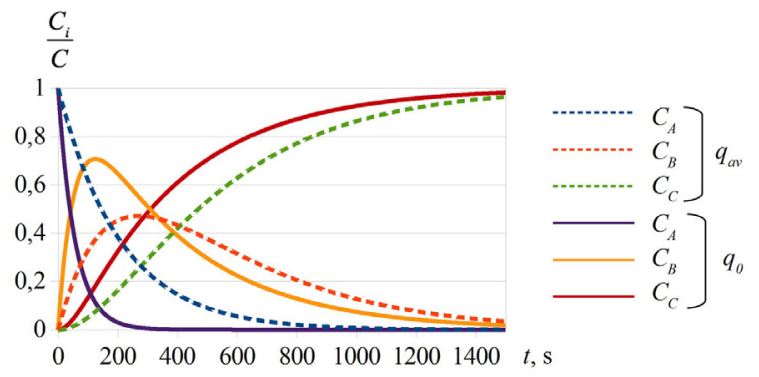

The graphs show that for the particles with low flotability, high value of superficial gas velocity plays a significant role. For the particles with high flotability, it is reasonable to decrease the superficial gas velocity by reducing the recycle water flow rate without decreasing the efficiency in comparison with the existing model.

\section{MATERIALS AND METHODS}

The experimental wastewater flotation treatment in a laboratory setup with pneumohydraulic system of aeration was carried out in order to verify the suggested modified flotation model.

\section{Laboratory setup}

The laboratory setup (Figure 4) consisted of aeration chamber -8 , pump -7 , compressor -5 , flotation cell-3, USB-microscope - 2, source of light -4 , computer -1 . The water and air flow rates were measured with $\mathrm{R} 1$ and $\mathrm{R} 2$ rotameters. Water circulated continuously in the setup, the air supplied by compressor 5 was sucked in the tube 6 . The air-water mixture went through the pump 7 and then through the aerator 9 where the bubble break-up happened into aeration chamber 8 . The water flow rate was $350 \mathrm{l} / \mathrm{h}$, air flow rate was $15 \mathrm{l} / \mathrm{h}$. USB-microscope 2 connected to computer 1 and source of light 4 were used for the video capture of bubbles and bubble-particle aggregates.

\section{Wastewater preparation}

The synthetic wastewater contained oil (petrol) and suspended solids. The following reagents were used:

- coagulant: $5 \%$ solution of Aqua-aurat-30, the dosage $-3.5 \mathrm{ml} / \mathrm{l}$;

- flocculant: $0.05 \%$ solution of Praestol-2540, the dosage $-1 \mathrm{ml} / 1$.

b)

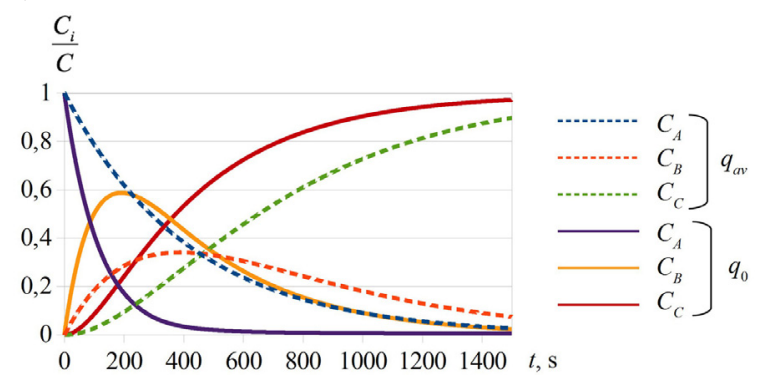

Figure 3. The solution of system of differential equations:

a) for the particles with high flotability, b) for the particles with low flotability 
a)

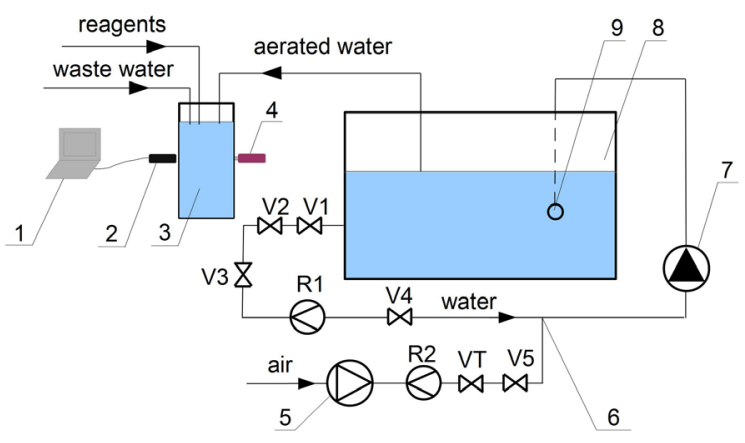

b)

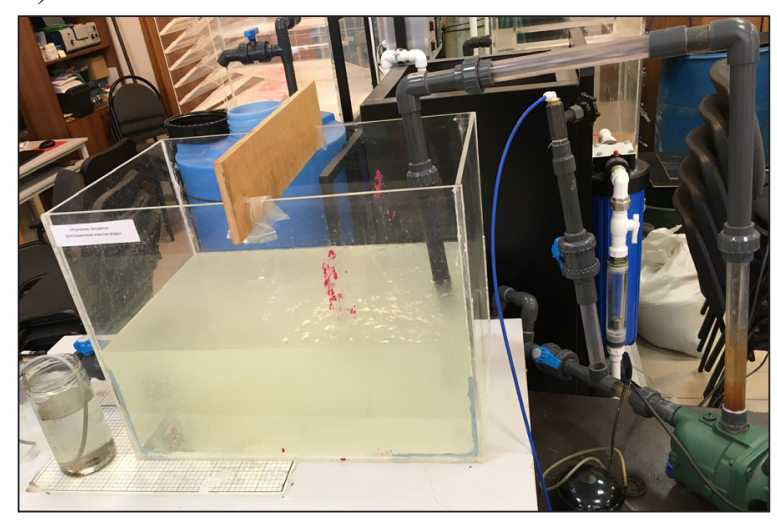

Figure 4. Laboratory setup a) scheme, b) photo: 1 - computer; 2 - USB-microscope; 3 - flotation cell; 4 - source of light; 5 - compressor; 6 - air inlet; 7 - pump; 8 - aeration chamber; 9 - aerator

\section{Experiment}

The series of three experiments were carried out, in which 1 liter of wastewater with previously added reagents was mixed with $300 \mathrm{ml}$ of aerated water from aeration chamber in flotation cell. The samples were taken at the initial moment and every two minutes during the flotation process. The samples were analyzed with Hach 2100N turbidimeter.

The bubbles and bubble-particle aggregates rising velocities were defined with the use of USB-microscope according to method presented in [Oliveira et al. 2010]. An example of bubbleparticle aggregate photo is presented in figure 5 .

The video of rising bubbles and bubble-particle aggregates was recorded and divided into frames. The distance between same bubbles or bubble-particle aggregates on two frames was measured. The rising velocity was defined as:

$$
v_{b, a g}=\frac{\Delta h}{\Delta t}
$$

where $\Delta h$-distance, $\mathrm{mm}$,

$\Delta t$ - duration of frame, s.

\section{RESULTS AND DISCUSSION}

The comparison of theoretical values obtained using the mathematical models with experimental results was made. The theoretical results represent the solution of system of differential equations Eq. (1) with constant superficial gas velocity (existing model) and varied superficial velocity (modified model). As only the sum $C_{\mathrm{A}}+C_{\mathrm{B}}$ can be defined experimentally, the theoretical curve is the sum of functions $C_{A}(t)+C_{B}(t)$.

The parameters used for the calculation of constants were obtained experimentally. The probability density functions of bubble-particle aggregates and bubbles rising velocities are presented in Figure 6.

The functions represent normal distribution and are characterized by the following values: bubble rising velocity is $2.5 \mathrm{~mm} / \mathrm{s}$ (standard deviation is $0.69 \mathrm{~mm} / \mathrm{s}$ ); bubble-particle aggregates rising velocity is $2 \mathrm{~mm} / \mathrm{s}$ (standard deviation is $0.58 \mathrm{~mm} / \mathrm{s}$ ).

The average size of bubbles generated by the pneumohydraulic system of aeration is $D=75 \mu \mathrm{m}$, superficial gas velocity is $q_{0}=2 \cdot 10^{-5} \mathrm{~m}^{3} /\left(\mathrm{m}^{2} \cdot \mathrm{s}\right)$. These parameters were defined previously [Antonova and Sazonov, 2019; Sazonov, 2017]. The other parameters are:

- time of period when $q_{0}=$ const: $t_{1}=30 \mathrm{~s}$;

- time of whole process: $T=720 \mathrm{~s}$;

- height of water level: $h=0.17 \mathrm{~m}$.

Average superficial rising velocity was calculated according to Eq. (8):

$$
\begin{aligned}
& q_{a v}=\frac{q_{0}}{T}\left(t_{1}+\frac{1}{k_{q}} \exp \left(-k_{q} t_{1}\right)\right)=\frac{2 \cdot 10^{-5}}{720} \times \\
& \times\left(30+\frac{1}{1.18 \cdot 10^{-2}} \exp \left(-1.18 \cdot 10^{-2} \cdot 30\right)\right)= \\
& =3.19 \cdot 10^{-6} \mathrm{~m}^{3} /\left(\mathrm{m}^{2} \cdot \mathrm{s}\right) .
\end{aligned}
$$

The values of constants calculated using formulas (3), (5), (6), (11) are: $k_{q}=1.47 \cdot 10^{-2} \mathrm{~s}^{-1}$, $K=2 \cdot 10^{-2} \mathrm{~s}^{-1}$ (for model with varied $q$ ), 

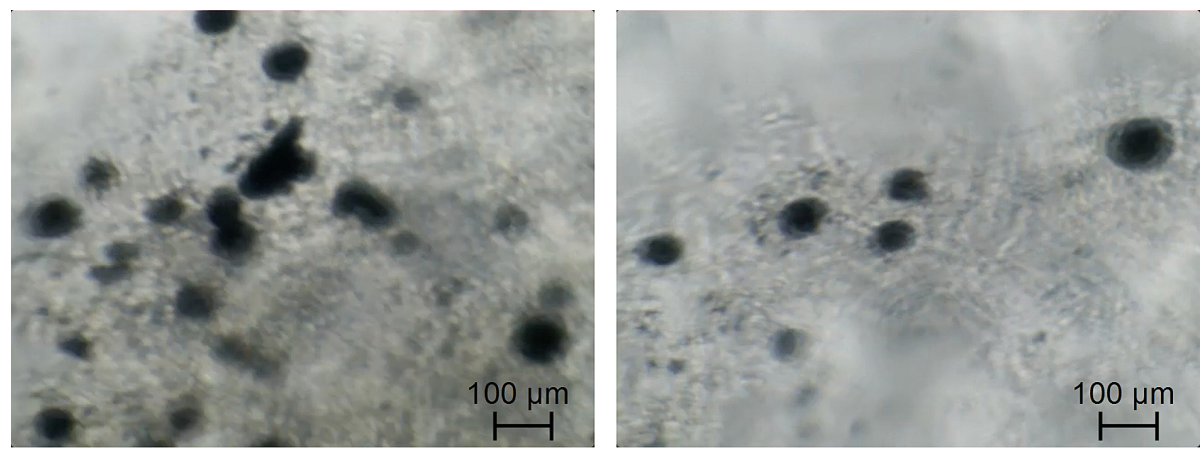

Figure 5. Bubble-particle aggregates

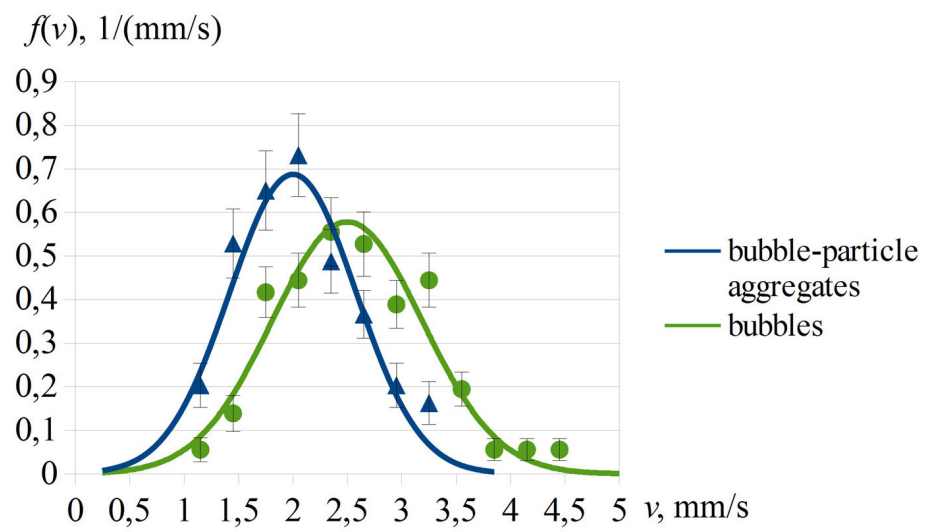

Figure 6. Rising velocity probability density functions

$k_{1}=3.19 \cdot 10^{-3} \mathrm{~s}^{-1}$ (for model with $q=\mathrm{const}=q_{a v}$ ), $k_{3}=1.18 \cdot 10^{-2} \mathrm{~s}^{-1}$, Due to the absence of turbulence in the period of bubble-particle aggregates rise, it is proposed that there are no reversible processes and as contamination contains suspended solids there is no self floating process, so $k_{2} \approx k_{4} \approx k_{5} \approx k_{6} \approx 0$.

The comparison of the experimental and theoretical data obtained using the model with constant and varied superficial rising velocity is presented in Figure 7.

The experimental data has a good correspondence with the theoretical curve that represents the modified flotation model with variable superficial gas velocity. The following peculiarities of process can be distinguished. Firstly, the treatment process proceeds quicker than the model with constant average superficial gas velocity predicts. Secondly, the residual concentration of contamination tends to the certain value, because not all particles form bubble-particle aggregates, while there are enough bubbles in water. This fact is especially important for the particles with low flotability. It proves the necessity of taking superficial gas velocity change in horizontal flow flotation tanks into consideration.

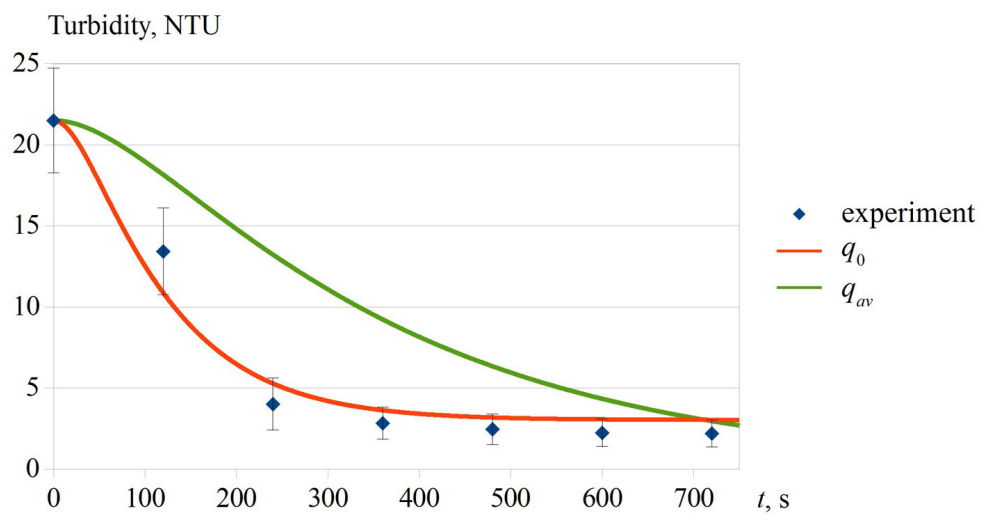

Figure 7. Experimental and theoretical results of wastewater flotation treatment 


\section{CONCLUSIONS}

The presented theoretical and experimental results proved the importance of superficial gas velocity change consideration in horizontal flow flotation tanks. The proposed model enables to define the superficial gas velocity in a more correct way without using the approximate value of cross-sectional area. Moreover, the model that uses average superficial gas velocity demands the excess air flow rate which leads to an increase in the ratio of air-water mixture and treated water flow rates, size of flotation tank and operation costs. The use of proposed modified model allows developing more efficient and less energyconsuming flotation tanks.

\section{REFERENCES}

1. Antonova E. S., Sazonov D. V. 2019. Increasing wastewater treatment efficiency in phneumohydraulic flotators. Water and Ecology: problems and solutions, 1 (77), 3-9 (In Russian). doi: 10.23968/23053488.2019.24.1.3-9

2. Brożek M. Młynarczykowska A. 2007. Analysis of kinetics models of batch flotation. Physicochemical Problems of Mineral Processing, 41, 51-65.

3. Bu X., Xie G., Peng Y., Ge L., Ni C. 2017. Kinetics of flotation. Order of process, rate constant distribution and ultimate recovery. Physicochemical Problems of mineral processing, 53(1), 342-365. doi: $10.5277 / \mathrm{ppmp} 170128$

4. Cheng G., Shi C., Yan X., Zhang Z., Xu H., Lu Y. 2017. A study of bubble-particle interactions in a column flotation process. Physicochemical Problems of Mineral Processing, 53(1), 17-33. doi: 10.5277/ppmp170102

5. Eskin A. 2017 Dissolved Air Flotation with Saturation of Liquid in Spray-Type Saturator. IOP Conf. Ser.: Mater. Sci. Eng. 262 012222. doi:10.1088/1 757-899X/262/1/012222

6. Edzwald J. K. 2010. Dissolved air flotation and me. Water research, 44(7), 2077-2106. doi:10.1016/j. watres.2009.12.040

7. Gurung A., Dahl O., Jansson K. 2016. The fundamental phenomena of nanobubbles and their behavior in wastewater treatment technologies. Geosystem Engineering, 19(3), 133-142. doi: 10.1080/12269328.2016.1153987

8. Guerrero-Pérez J. S., Barraza-Burgos, J. M. 2017. A new mathematical model for coal flotation kinetics. Dyna, 84(203), 143-149. doi: 10.15446/dyna. v84n203.62593

9. Haarhoff J., Edzwald J. K. 2004. Dissolved air flotation modelling: insights and shortcomings. Journal of Water Supply: Research and Technology-AQUA, 53(3), 127-150.

10. Kouachi S., Bouhenguel M., Amirech A., Bouchemma A. 2010. Yoon-Luttrell collision and attachment models analysis in flotation and their application on general flotation kinetic model. Desalination, 264(3), 228-235. doi:10.1016/j.desal.2010.06.057

11. Kracht W., Vallebuona G., Casali A. 2005. Rate constant modelling for batch flotation, as a function of gas dispersion properties. Minerals Engineering, 18(11), 1067-1076.

12. Ksenofontov B. S. 2010. Flotatsionnaya obrabotka vody, otkhodov i pochvy [Flotation Treatment of Water, Waste and Soil]. Novye Tekhnologii Publ., Moscow (In Russian).

13. Oliveira C., Rodrigues R. T., Rubio J. 2010. A new technique for characterizing aerated flocs in a flocculation-microbubble flotation system. International Journal of Mineral Processing, 96(1-4), 36-44. doi:10.1016/j.minpro.2010.07.001

14. Polat M., Chander, S. 2000. First-order flotation kinetics models and methods for estimation of the true distribution of flotation rate constants. International Journal of Mineral Processing, 58(1-4), 145-166.

15. Prakash R., Majumder S. K., Singh A. 2018. Flotation technique: Its mechanisms and design parameters. Chemical Engineering and Processing-Process Intensification, 127, 249-270. doi: 10.1016/j. cep.2018.03.029

16. Saththasivam J., Loganathan K., Sarp S. 2016. An overview of oil-water separation using gas flotation systems. Chemosphere, 144, 671-680. doi: doi. org/10.1016/j.chemosphere.2015.08.087

17. Sazonov D. V. 2017. Influence of the pump type on the parameters of the pneumatic-hydraulic aeration system in flotation apparatus. Water supply and sanitary technique, 10, 40-45 (In Russian).

18. Shahbazi B., Rezai B., Koleini S. M. J., Noparast M. 2013. The effect of bubble surface area flux on flotation efficiency of pyrite particles. Iranian Journal of Chemistry and Chemical Engineering (IJCCE), 32(2), 109-118.

19. Vazirizadeh A. 2015. The relationship between hydrodynamic variables and particle size distribution in flotation. Ph.D. Thesis, Université Laval, Quebec.

20. Yianatos J. B. 2007. Fluid flow and kinetic modelling in flotation related processes: Columns and mechanically agitated cells-a review. Chemical Engineering Research and Design. 85(A12),1591-1603. doi: 10.1016/s0263-8762(07)73204-5 